\title{
Comparison between Displacement of PVC and Silicone Double- Lumen Endobronchial Tube during Lateral Positioning
}

\author{
Eui Kyun Jeong1, Jihyoung Park², Yong Il Kim³ , and Kwang Ho Lee ${ }^{4 *}$ \\ ${ }^{I}$ Department of Anesthesiology, Gangneung Asan Hospital, University of Ulsan College of Medicine, \\ (Gangneung, Korea) \\ 2, 3, ${ }^{4}$ Department of Anesthesiology and Pain Medicine, Yonsei University Wonju College of Medicine, (Wonju, \\ Korea)
}

*Corresponding Author: Kwang Ho Lee, Department of Anesthesiology and Pain Medicine, Yonsei University Wonju College of Medicine, (Wonju, Korea), Email: khlee6006@yonsei.ac.kr

\begin{abstract}
Background: A position change after placing a double-lumen endobronchial tube (DLT) frequently results in tube displacement. In this study, we compared displacement of polyvinyl chloride (PVC) and silicone DLTs during lateral positioning.
\end{abstract}

Methods: We enrolled 80 patients undergoing thoracic surgery whose positions were changed to lateral decubitus after DLT insertion. After DLT intubation, the distance (TD) between the carina and tracheal opening of the DLT was measured with a bronchoscope in both supine and lateral positions. We also measured the distances $(B D)$ between the left second carina and left bronchial opening of the DLT. DLT movement was measured by subtracting the tracheal $(\triangle T D)$ and bronchial distances $(\triangle B D)$ in the supine position from those in the lateral position.

Results: The $\triangle T D$ and $\triangle B D$ differed significantly between the PVC and silicone groups $[\triangle T D 8.8 \pm 7.6 \mathrm{~mm}$ $(-13-30 \mathrm{~mm})$ vs. $5.8 \pm 4.9(-14-17 \mathrm{~mm}), \triangle B D 10.4 \pm 8.3(-14-35 \mathrm{~mm}) \mathrm{vs} .6 .7 \pm 6.7 \mathrm{~mm}(-15-27 \mathrm{~mm})$ for PVC vs. silicone DLTs, respectively].

Conclusion: A silicone DLT can reduce displacement of DLT during lateral position change when compared with a PVC DLT.

Keywords: Displacement, Double-lumen endobronchial tube, Position change, silicone DLT

Abbreviations: $D L T=$ Double-lumen endobronchial tube, $P V C=$ Polyvinyl chloride, $T D=$ tracheal distance, $B D=$ bronchial distance, $\triangle T D=$ subtracting the tracheal distances in the supine position from those in the lateral position, $\triangle B D=$ subtracting the bronchial distances in the supine position from those in the lateral position, $F O B=$ fiber optic bronchoscope

\section{INTRODUCTION}

Double-lumen endobronchial tube (DLT) intubation is essential for one-lung ventilation during thoracic surgery [1]. However, if the DLT is displaced, it may cause difficulties in maintaining one-lung ventilation and operation procedures. Even though the tube may be positioned correctly after intubation, DLT displacement has been reported during lateral position change [2]. Neck movement is known to influence DLT position [3]. Therefore, methods to minimize neck movement during position changes are recommended [4]. Polyvinyl chloride (PVC) DLTs are hard, so, depending on the extent of neck movement, there may be significant DLT movement.

We postulated that the flexibility of a silicone
DLT will allow it to bend during cervical movement, reducing tube movement. Therefore, we compared displacement of PVC and silicone DLTs during a position change.

\section{MeThODS}

This study was conducted under the approval of the Ethics Committee of our hospital, and informed consent was obtained from all patients. The patient ages ranged from 20 to 67 years, who were scheduled to undergo left or right thoracic procedures requiring one-lung ventilation in the lateral decubitus position. Left-side DLT was used in all patients. All data were obtained by an anesthesiologist with experience with more than 500 intubations. Forty patients each were assigned to the PVC or silicon group. Within each group, 20 patients 
were positioned in right lateral decubitus, and the remaining 20 were positioned in left lateral decubitus. Patients with severe respiratory dysfunction, and severe deformities of the trachea or bronchial structures on chest X-ray were excluded.

After attaching monitoring devices, anesthesia was induced with propofol $2.0 \mathrm{mg} / \mathrm{kg}$, remifentanil $0.15 \mu \mathrm{g} / \mathrm{kg} / \mathrm{min}$ and rocuronium 0.8 $\mathrm{mg} / \mathrm{kg}$. Patients were divided into two groups: intubation with PVC DLT (Broncho-cath ${ }^{\circledR}$, Mallinckrodt Medical Ltd., Athlone, Ireland) or silicone DLT (Human broncho, Insung Medical Co Ltd., Korea). The tube size (\#35 or \#37 French) was selected after considering the patient's gender and height. After positioning an $8 \mathrm{~cm}$ pillow under the patient's head, intubation was performed. Then fiber optic bronchoscope (FOB, Olympus LF-DP, Olympus Optical Co., Tokyo, Japan) was used to confirm that the bronchial cuff of the DLT was located just under the carina. The tube was then firmly fixed at the side of the mouth with tape. Using the FOB, the distance from the opening of the tracheal lumen to the carina (tracheal distance, TD) and the distance from the opening of the bronchial lumen to the left second carina (bronchial distance, BD) were measured. Tracheal and bronchial distances were measured as described previously [5]. To measure the TD, the end of the FOB was placed in the carina through the tracheal lumen of the DLT, and the FOB was marked with black at the elbow connector opening of the DLT. Then, the FOB was pulled back so the end was at the tracheal opening of the DLT, and the FOB was marked with blue at the elbow connector opening of the DLT. The distance between the black and blue marks was the TD. The BD was measured by using the same method. The FOB was inserted through the DLT bronchial lumen and positioned at the left second carina. The distance between the black and blue marks is the bronchial distance.

After deflating the bronchial cuff of the DLT, the patient's position was changed from supine to lateral decubitus. The DLT was wrapped around the patient's mouth firmly and caution was taken so that the tube did not fall out of the mouth during the position change. One hand was used to hold the tube and face, and the other was placed behind the neck and back. The auxiliary roll was placed under the dependent axillary side with a pillow under the patient's head, and the surgical bed was adjusted. TD and
$\mathrm{BD}$ were measured in the same manner as the first measurement. DLT movement was measured by subtracting the tracheal $(\triangle T \mathrm{TD})$ and bronchial distances $(\triangle \mathrm{BD})$ in the supine position from those in the lateral position. A negative value meant that the tube moved in, and a positive value meant that the tube moved out. Inward or outward movement of more than 10 $\mathrm{mm}$ was defined as significant.

Statistical analysis: To identify differences between the PVC and silicone DLTs, a hypothesis test was performed to compare the two groups based previous methods [6, 7]. The significance level was set at 0.05 , and the power was $80 \%$. For each group, 37 samples were calculated. Considering a dropout rate of $10 \%$, a total of 40 people were needed, so a total of 80 subjects (left 40 and right 40 ) were analyzed. Each group was alternately selected continuously. Sampling was terminated when data collection of 20 patients were complete. When 4 groups of 20 subjects were formed, subject collection was terminated.

The data are expressed as mean \pm SD (range). Negative values refer to distal movement. A two-sample t-test was performed to compare continuous variables. Categorical variables were compared with the chi-square or Fisher's exact test. To confirm differences in $\triangle \mathrm{BD}$ and $\triangle \mathrm{TD}$ variations between the PVC and silicone groups, Wilcoxon rank sum test was used. A Chi-square test was performed to confirm differences in the proportions of $\mathrm{BD}$ and $\mathrm{TD}$ displacements over $10 \mathrm{~mm}$ between the PVC and silicone groups. All analyses were performed with the SAS statistical package (version 9.4, SAS Institute Inc., Cary, NC, USA).

\section{RESUltS}

Demographic data did not differ significantly between groups (Table 1).

Table1. Demographic data. Values represent mean \pm SD. BMI: body mass index. There was no significant difference between the groups. PVC: polyvinyl chloride, DLT: double-lumen endotbronchial tube,

\begin{tabular}{|l|l|l|l|l|l|l|l|}
\hline & \multicolumn{3}{|c|}{$\begin{array}{c}\text { PVC DLT } \\
(\mathbf{n = 4 0})\end{array}$} & \multicolumn{3}{c|}{$\begin{array}{c}\text { Silicone DLT } \\
(\mathbf{n = 4 0})\end{array}$} & P value \\
\hline Age (yr) & 44.7 & \pm & 21.4 & 47.1 & \pm & 21.0 & 0.622 \\
\hline Sex (M/F) & \multicolumn{2}{|c|}{$33 / 7$} & \multicolumn{3}{|c|}{$29 / 11$} & 0.284 \\
\hline $\begin{array}{l}\text { Weight } \\
(\mathrm{kg})\end{array}$ & 61.5 & \pm & 9.6 & 59.9 & 10.3 & & 0.466 \\
\hline $\begin{array}{l}\text { Height } \\
(\mathrm{cm})\end{array}$ & $\begin{array}{l}167 . \\
8\end{array}$ & \pm & 10.6 & 165.5 & 9.3 & & 0.325 \\
\hline BMI & 22.0 & \pm & 4.3 & 21.9 & 3.8 & & 0.885 \\
\hline
\end{tabular}


$\triangle \mathrm{TD}$ and $\triangle \mathrm{BD}$ were significantly lower in the silicone group $[\Delta \mathrm{TD} 8.8 \pm 7.6 \mathrm{~mm}(-13-30)$ vs. $5.8 \pm 4.9 \mathrm{~mm}(-14-17), \mathrm{P}=0.040, \Delta \mathrm{BD} 10.4 \pm$ $8.3 \mathrm{~mm}(-14-35)$ vs. $6.7 \pm 6.7 \mathrm{~mm}(-15-27)$, $\mathrm{P}=0.031$ for $\mathrm{PVC}$ vs silicone group, respectively] (Fig 1). DLT tended to move out more often than moving in; however, this trend did not differ significantly between groups (Table 2).

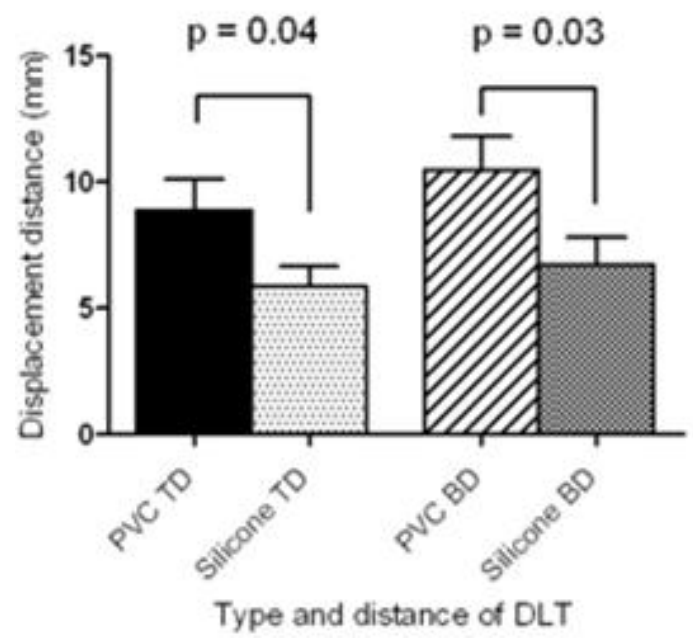

Figure1. Displacement of PVC and silicone doublelumen endobronchial tubes. Data presented as position change in millimeters. PVC: polyvinyl chloride, DLT: double-lumen endobronchial tube. There was a significant difference in the distance of movement between the groups.

Table2. Tracheal and bronchial displacement more than $10 \mathrm{~mm}$. Data are number of patients (\%). PVC: polyvinyl chloride, DLT: double-lumen endotbronchial tube, LLD: left lateral decubitus, RLD: right lateral decubitus, TD: tracheal distance, BD: bronchial distance.

\begin{tabular}{|l|l|l|l|l|}
\hline \multicolumn{1}{|c|}{ TD } & \multicolumn{2}{c|}{$\begin{array}{c}\text { PVC DLT } \\
(\mathbf{n = 4 0})\end{array}$} & \multicolumn{2}{c|}{$\begin{array}{c}\text { Silicone DLT } \\
(\mathbf{n = 4 0})\end{array}$} \\
\hline Position (n=20) & LLD & RLD & LLD & RLD \\
\hline $\begin{array}{l}\text { Proximal } \\
\text { Direction(\%) }\end{array}$ & $7(35)$ & $7(35)$ & $3(15)$ & $5(25)$ \\
\hline Distal direction(\%) & $1(5)$ & $1(5)$ & $0(0)$ & $1(5)$ \\
\hline $\begin{array}{l}\text { Displacement } \\
<10 m m \%\end{array}$ & $12(60)$ & $12(60)$ & $17(85)$ & $14(70)$ \\
\hline P value & \multicolumn{2}{|c|}{1.000} & \multicolumn{2}{c|}{0.450} \\
\hline
\end{tabular}

\begin{tabular}{|l|l|l|l|l|}
\hline \multicolumn{1}{|c|}{ BD } & \multicolumn{2}{|c|}{$\begin{array}{c}\text { PVC DLT } \\
(\mathbf{n}=\mathbf{4 0})\end{array}$} & \multicolumn{2}{|c|}{$\begin{array}{c}\text { Silicone DLT } \\
(\mathbf{n}=40)\end{array}$} \\
\hline Position (n=20) & LLD & RLD & LLD & RLD \\
\hline $\begin{array}{l}\text { Proximal } \\
\text { direction(\%) }\end{array}$ & $9(45)$ & $7(35)$ & $2(10)$ & $8(40)$ \\
\hline Distal direction(\%) & $1(5)$ & $0(0)$ & $2(10)$ & $0(0)$ \\
\hline $\begin{array}{l}\text { Displacement } \\
<10 \text { mm (\%) }\end{array}$ & $10(50)$ & $13(65)$ & $16(80)$ & $12(60)$ \\
\hline P value & 0.523 & & 0.036 \\
\hline
\end{tabular}

ARC Journal of Anesthesiology
The difference between RLD and LLD positions was significant only in $\triangle \mathrm{BD}$ of the silicone group; $\triangle \mathrm{TD}$ of the silicone group and $\triangle \mathrm{BD}$ and $\triangle \mathrm{TD}$ of the PVC group showed no statistically significant differences. ( $\triangle$ TD $9.4 \pm 7.9$ vs. $8.3 \pm$ 7.6 $\mathrm{P}=0.886, \Delta \mathrm{BD} 11.9 \pm 8.4$ vs. $9.0 \pm 8.1 \mathrm{P}=$ 0.757 , PVC group LLD vs. RLD respectively, $\Delta$ TD $6.8 \pm 5.4$ vs. $4.9 \pm 4.3 \mathrm{P}=0.215, \Delta \mathrm{BD} 8.8$ \pm 7.9 vs. $4.6 \pm 4.5 \mathrm{p}=0.018$, silicone group LLD vs. RLD, respectively)

Both $\triangle \mathrm{TD}$ and $\triangle \mathrm{BD}$ changes of more than 10 $\mathrm{mm}$ were more common in the PVC group, but the difference was not significant [ $\triangle \mathrm{TD} 16$ (40\%) / 9 (22.5\%), $\Delta \mathrm{BD} 17$ (42.5\%) / 12 (30\%), $\mathrm{PVC}$ vs. silicone group, respectively] (Table 2).

\section{DISCUSSION}

A position change after placing a DLT frequently results in tube displacement. DLT movement of more than $5 \mathrm{~mm}$ has been reported in $46 \%$ of patients after lateral position change [8]. Many factors can cause this displacement [8]. Neck flexion and extension can displace the DLT. Depending on the extent of neck flexion and extension, the DLT movement can differ. The DLT moves in during neck flexion and out during extension. Saito et al. [9] reported that the mean movement of the distal tip during neck flexion and extension is about $27 \mathrm{~mm}$ (15-33). Therefore, applying a neck brace may minimize neck movement during a lateral position change [7]. Displacement can also occur during a position change from supine to lateral. When a patient's head is placed on a headrest, the DLT is positioned with the patient's neck flexed. In lateral positioning, the patient's neck is extended, and the DLT may move outward. Therefore, after DLT intubation with a headrest, adjusting the DLT and changing positions without a headrest would minimize tube displacement [7]. Surgical manipulation, such as lung traction, can also cause the DLT to move during surgery.

According to the results of this study, difference of DLT movement depends on material of DLT. We found that a silicone DLT minimized tube displacement in the lateral positioning when compared to a PVC DLT. This is because the external force applied during neck flexion and extension is different in two groups of DLT. The force is fully transmitted in stiff, PVC material, but less in flexible, Silicone DLT. Right and left lateral positioning did not cause difference in displacement of DLT except in silicone group's 
BD. This result shows that gravity does not play an important role in DLT displacement $[4,7]$. Tracheal and bronchial displacement during lateral positioning are not constant, and changes in $\triangle \mathrm{TD}$ and $\triangle \mathrm{BD}$ do not differ significantly $[7,10]$. In this study, tube movement differed significantly between two groups $(\triangle \mathrm{TD} 8.8 \mathrm{~mm}$ vs. $5.8 \mathrm{~mm}, \triangle \mathrm{BD} 10.4 \mathrm{~mm}$ vs $6.7 \mathrm{~mm}$, PVC vs silicone group, respectively).

We assumed that tube displacement greater than $10 \mathrm{~mm}$ may affect one-lung ventilation and lung collapse during surgery. Compared to the silicone group, more patients in the PVC group $(\Delta \mathrm{TD} 40 \%$ vs. $22.5 \%, \Delta \mathrm{BD} 42.5 \%$ vs. $30 \%$, PVC vs. silicone group, respectively) displayed movement greater than $10 \mathrm{~mm}$ in distance, but this was not statistically significant. Lee et al. [11] showed a significant difference (44.8\% vs. $4.8 \%$, PVC vs. silicone group, respectively) between DLT displacements in their two groups than in our study. In their study, when first positioning DLT, the radio-opaque line on the DLT was located at the carina. Meanwhile, for Silbroncho ${ }^{\circledR}$ (Fugi, Japan), the radio-opaque line was positioned $2 \mathrm{~cm}$ above the bronchial cuff, and, for broncho-cath ${ }^{\circledR}$, the radio-opaque line was located $1 \mathrm{~cm}$ above the bronchial cuff. The difference might thus be due to the deep initial position of radio-opaque line.

\section{CONCLUSION}

Lateral position change after DLT intubation causes DLT movement in many cases. However, a silicone DLT rather than a PVC DLT may reduce DLT displacement during a position change.

\section{REFERENCES}

[1] Lewis JW, Sherwin JP, Gabriel FS, Bastanfar M, Jacobsen G. The utility of a double-lumen tube for one-lung ventilation in a variety of noncardiac thoracic surgical procedures, $\mathrm{J}$ Cardiothorac Vasc anesth. 6 (1992).

[2] Bussières JS, Slinger P. Correct positioning of double-lumen tubes, Can J Anesth . 59(2012).
[3] Lee KH, Lim HK, Yoon KB, Um DJ, Lim HK. Movement of double-lumen endobronchial tubes during position change, Korean $\mathrm{J}$ Anesthesiol. 27(1994).

[4] Seo JH, Hong DM, Lee JM, Chung EJ, Bahk JH. Double-lumen tube placement with the patient in the supine position without a headrest minimizes displacement during lateral positioning, Can J Anesth. 59(2012).

[5] Bennumof JL, Partridge BL, Salvatierra C, Keating J. Margin of safety in positioning modern double-lumen endotracheal tubes, Anesthsiology. 67(1987).

[6] Desiderio DP, Burt M, Kolker AC, Fischer ME, Reinsel R, Wilson RS. The effects of endobronchial cuff inflation on double-lumen endobronchial tube movement after lateral decubitus positioning, J Cardiothorac Vascu Anesth. 11(1997).

[7] Yoon TG, Chang HW, Ryu HG, Kwon TD, Bahk JH. Use of a neck brace minimizes double-lumen tube displacement during patient positioning, Can J Anaesth. 52(2005).

[8] Klein U, Karzai W, Bloos F, wohlfarth M, Gottschall R. Fritz H, Seifert A. Role of fiberoptic bronchoscopy in conjunction with the use of double-lumen tubes for thoracic anesthesia: a prospective study, Anesthesiol. 88(1998).

[9] Saito S, Dohi S, Naito H. Alteration of doublelumen endobronchial tube position by flexion and extension of the neck, Anesthesiology. 62(1985).

[10] Desiderio DP, Burt M, Koller AC, Fischer ME, Reinsel R, Wilson RS. The effects of endobronchial cuff inflation on double-lumen endobronchial tube movement after lateral decubitus positioning, J Cardiothorac Vasc Anesth. 11(1997).

[11] Lee JS, Kil TY, Chung JY. Comparison of a silicon double-lumen endobronchial tube $\left(\right.$ Silbroncho ${ }^{\circledR}$ ) with a polyvinyl chloride tube (Broncho-cath ${ }^{\circledR}$ ) in right-side thoracic surgery, Korean J Anesthesiol. 48(2005).

Citation: Eui Kyun Jeong, Jihyoung Park, Yong Il Kim, and Kwang Ho Lee. Comparison between Displacement of PVC and Silicone Double-Lumen Endobronchial Tube during Lateral Positioning. ARC Journal of Anesthesiology. 2018; 3(2):1-4. DOI: dx.doi.org/10.20431/2455-9792.0302001.

Copyright: () 2018 Authors. This is an open-access article distributed under the terms of the Creative Commons Attribution License, which permits unrestricted use, distribution, and reproduction in any medium, provided the original author and source are credited. 